\title{
Digital divide Mobile internet speeds in the Pacific
}

\begin{abstract}
This article outlines mobile internet speeds experienced by 15 smartphone users in the Pacific region. It presents new quantitative data collected over a six-month-long period. The data were collected in order to provide a comparison of places and to look for trends over time. The research was adjusted for confounding factors like weather and building type. The findings indicate substantial differences between the internet speeds and reliability experienced in Australian cities compared to the readings in Pacific Island locations. Over the six-month-long period, there were no substantial improvements or decreases in internet speeds at any of the included locations. This finding takes into account changes in weather, time of day and surroundings. As expected, clear skies and outdoor settings were positively associated with faster internet speeds, compared to rainy periods and indoor readings in the same geographical areas.
\end{abstract}

Keywords: Cell phone, communication, internet, Melanesia, mobile phone, Pacific, Pacific studies, phone, smartphone, technology, telecommunications, telephone

\section{AMANDA H. A. WATSON \\ ROHAN FOX \\ Australian National University, Canberra}

\section{Introduction}

NTERNET access is uneven across the Pacific region (UN ESCAP, 2018) but is 'generally still lacking' (UN ESCAP, 2018, p. 12) compared to other parts of the world. For those with access to the internet, a common method of going online is to use a mobile telephone, rather than a tablet, laptop or desktop computer (Williams, 2019, p. 5). Mobile telephone access and uptake varies between countries in the Pacific. For instance, the subscriber penetration rate is 84 percent in Fiji but only 17 percent in the Federated States of Micronesia (GSMA, 2019, p. 7).

Infrastructure that enables internet access has improved recently. In 2018, 'Fiji was connected to the Tui-Samoa undersea cable, which in turn connects to the major Southern Cross cable that provides direct links to the US [United States] and New Zealand' (GSMA, 2019, p. 20). The Coral Sea Cable System includes a domestic undersea cable within Solomon Islands and it also links Solomon Islands and Papua New Guinea to Sydney, Australia. It was completed 
in December 2019. The Kumul Submarine Cable is a domestic cable throughout Papua New Guinea undergoing testing at the time of writing. The Manatua One Polynesia Cable was completed in 2020 and connects Cook Islands, Niue, Samoa, and French Polynesia. These cables increase capacity and assertions have been made that they will enable faster internet speeds (GSMA, 2019; Highet, Nique, Watson, \& Wilson, 2019; Williams, 2019).

This article examines the mobile internet speeds available to smartphone users in Pacific Island nations. Comparison is made with the speeds experienced by users in urban and rural locations in nearby Australia. The focus of the paper is presenting quantitative data - that is, the internet speeds themselves and statistical analysis thereof, including regressions. The article makes a contribution to the understanding of the experiences of people in the Pacific when they try to communicate or access information using the internet.

\section{The digital divide lens}

The 'digital divide' term was coined to refer to a disparity in access to information and communication technologies (Ball et al., 2019, p. 1169; Ragnedda, 2018; Sagrista \& Matbob, 2016; van Dijk, 2005, p. 1). This term was defined as 'the gap between those who do and those who do not have access to computers and the internet' (van Dijk, 2005, p. 1). Although some scholars critique 'the arbitrary, binary nature of the concept of a digital divide' (Donner, 2015, p. 50), it is a useful lens through which to view this research. Someone who attempts to use the internet but has access to very low internet speeds cannot be considered to have the same access as a person who experiences fast internet speeds. There is a divide - $\mathrm{a}$ 'digital divide' - between these two internet users.

\section{Background and context}

Historically, there have long been inequalities in societies, for instance with regard to income levels, location and education. In contemporary times, 'with increasing technological global dependency, the digital divide has become one of the most significant social divides' (Rogerson, 2020). Multiple factors interact in complex ways (Rogerson, 2020), so that 'social inequalities are strongly intertwined with digital inequalities' (Robinson et al., 2020, n.p.). The people of the Pacific region do not enjoy the internet access that is common in many parts of the world (GSMA, 2019). Indeed, as advances are made elsewhere, it could be argued that the gap between the Pacific and other regions is widening (UN ESCAP, 2018, p. 13). It is this 'digital divide' that this research seeks to investigate.

Internet accessibility and affordability can be linked to the provision of public infrastructure such as roads and electricity. A limited road network in Papua New Guinea (Curry, Dumu, \& Koczberski, 2016, pp. 41-42; World Bank, 2020, pp. 35-38) directly contributes to costs for telecommunication companies (Highet 
et al., 2019, p. 22). Electricity is required for internet provision and for consumer devices. Because 'most Pacific Island countries generate electricity from diesel fuel' (UN ESCAP, 2018, p. 31), there can be insufficient electricity capacity and high prices (UN ESCAP, 2018, p. 31), making it difficult to increase internet access and use. For example, Papua New Guinea has very limited electricity provision (Highet et al., 2019, p. 23; Williams, 2019, p. 3; World Bank, 2020, pp. 33-34) and thus many mobile telephone towers require costly solar systems and backup diesel generators (Highet et al., 2019, p. 22).

Telecommunications services have large fixed costs, so where there is a small population, such as in a Pacific Island nation, there would tend to be limited economies of scale (GSMA, 2019, p. 5). This may lead to poor services, high prices and possibly low speeds on average, for instance if a telecommunication company chooses to install a $2 \mathrm{G}$ or $3 \mathrm{G}$ network rather than to invest in the latest generation network.

A similar outcome could occur if there is limited competition. According to the GSMA, 'the most favourable market structure for promoting investment and innovation is one with two or three mobile operators' $(2019$, p. 11). In the Pacific region, there is limited market competition in the mobile telephony sector (GSMA, 2019). Out of 23 countries and territories, 13 have only one active mobile operator (GSMA, 2019, pp. 11-12).

\section{The link to media and journalism}

A key component of a functioning democracy is a citizenry that is well-informed and actively engaged in debates about governance, social and economic issues and relevant government policies (ABC International Development, 2014). Thus, it is important that citizens have the means to communicate their views and concerns. To formulate such opinions, citizens should ideally have access to timely information. Internet access can enable such communication and information gathering (Sagrista \& Matbob, 2016). In addition, the media has a crucial role to play in this regard (Singh, 2020). If a journalist wishes to interview someone about a development project or natural disaster in their area, fast internet in that location could enable a video call of sufficient quality to be broadcast on television. Slow and unreliable internet would make such an interview impossible. Thus, mobile internet speeds can have an impact upon the functioning of the media and upon the ability for a diverse range of voices to be heard.

\section{Technical terms}

Three measures of internet quality that are used in this study are download speed, upload speed and ping speed. Download speeds are relevant 'when information (or "data") is received' (Telstra, n.d.) by a device from the internet, for example, 


\begin{tabular}{|l|c|}
\hline Table 1: Recommended download speeds for streaming \\
\hline Audio & 1.5 \\
\hline Standard definition video & 3 \\
\hline HD video & $4-5$ \\
\hline Ultra HD video & $15-25$ \\
\hline Zoom conferencing & $10-25$ (download), 3 (upload) \\
\hline
\end{tabular}

Note: Recommended download speeds required to stream (MB/s) Sources: (AT Services, 2021; Frontier, 2021; Harris, 2019)

when a website is opened or when a video is being watched. Download speeds are measured in megabytes per second $(\mathrm{MB} / \mathrm{s})$, or kilobytes per second $(\mathrm{KB} / \mathrm{s})$ for slower speeds. A rough sketch of the download speeds required for various activities is presented in Table 1 .

Upload speeds apply "when you send data from your device to somewhere else' (Telstra, n.d.), for example when uploading a video to YouTube or sending audio and video of yourself speaking in a video call. Upload speeds are also measured in megabytes per second $(\mathrm{MB} / \mathrm{s})$ or kilobytes per second $(\mathrm{KB} / \mathrm{s})$ and are generally lower than download speeds.

Ping speeds measure the time taken for the mobile telephone signal to reach the nearest internet server. Ping speeds are measured in milliseconds (ms), which are a thousandth of a second. Ping speeds are mainly relevant to higherend internet users who require fast connection speeds and very low latency times, such as for online gaming (nbn co ltd, 2020). Technically, 'ping' is the process while the measurement is the 'latency' but the two terms are often used interchangeably (nbn co ltd, 2020) and in this paper we refer to 'ping speeds'. Because ping speeds capture the travel time of data, they are largely determined by the device's physical distance from the server. Ping speeds can be affected by server congestion, the type of connection and the available bandwidth. Low ping speeds indicate a good quality internet connection.

Technical advances in mobile telephone network and handset types are referred to as technological generations (Watson \& Park, 2019). First generation or $1 \mathrm{G}$ technology enables analogue mobile telephones, including car telephones. Second generation or $2 \mathrm{G}$ service is the first iteration of digital mobile telephone technology. Third generation $(3 \mathrm{G})$ is the first technology suitable for using the internet on mobile telephones, while $4 \mathrm{G}$ and $5 \mathrm{G}$ technologies allow for quicker internet browsing (Watson \& Park, 2019).

\section{Methods}

This research project aimed to determine the mobile internet speeds experienced by 15 consumers in five Pacific Island nations, with comparison to neighbouring Australia. The aim was to determine differences between experiences 


\begin{tabular}{|c|c|c|c|c|}
\hline Country & $\begin{array}{l}\text { Location } \\
\text { Name }\end{array}$ & Type of location & $\begin{array}{l}\text { Mobile } \\
\text { network }\end{array}$ & Handset type \\
\hline \multirow{3}{*}{ Australia } & Sydney & Large urban centre & Optus & Oppo R15 \\
\hline & Canberra & Large urban centre & Telstra & Samsung S10 \\
\hline & Balranald & $\begin{array}{l}\text { Rural town in New } \\
\text { South Wales }\end{array}$ & Telstra & $\begin{array}{l}\text { iPhone Xs } \\
\text { Max }\end{array}$ \\
\hline $\begin{array}{l}\text { Federated } \\
\text { States of } \\
\text { Micronesia }\end{array}$ & Colonia & $\begin{array}{l}\text { Small urban centre in } \\
\text { Yap state, and some } \\
\text { readings in rural } \\
\text { areas on the same } \\
\text { island }\end{array}$ & FSM Telecom & iPhone4 \\
\hline Fiji & Suva & $\begin{array}{l}\text { Medium-sized urban } \\
\text { centre }\end{array}$ & $\begin{array}{l}\text { Unwired, a } \\
\text { subsidiary of } \\
\text { Digicel }\end{array}$ & $\begin{array}{l}\text { Samsung A20 } \\
\text { and then Sam- } \\
\text { sung A20s }\end{array}$ \\
\hline \multirow{5}{*}{$\begin{array}{l}\text { Papua New } \\
\text { Guinea }\end{array}$} & Lae & Large urban centre & Digicel & Samsung J1 \\
\hline & $\begin{array}{l}\text { Madang } \\
\text { (user 1) }\end{array}$ & $\begin{array}{l}\text { Medium-sized } \\
\text { urban centre, and } \\
\text { some readings in a } \\
\text { rural area of the same } \\
\text { province }\end{array}$ & Digicel & Oppo F7 \\
\hline & $\begin{array}{l}\text { Madang } \\
\text { (user 2) }\end{array}$ & $\begin{array}{l}\text { Medium-sized } \\
\text { urban centre, and } \\
\text { some readings in a } \\
\text { rural area of the same } \\
\text { province }\end{array}$ & Telikom & Oppo F7 \\
\hline & $\begin{array}{l}\text { Mount } \\
\text { Hagen }\end{array}$ & $\begin{array}{l}\text { Medium-sized } \\
\text { urban centre, and } \\
\text { some readings in a } \\
\text { rural area of the same } \\
\text { province }\end{array}$ & Digicel & Samsung J2 \\
\hline & \begin{tabular}{|l} 
Port \\
Moresby \\
\end{tabular} & Large urban centre & Telikom & Samsung A30 \\
\hline \multirow[b]{2}{*}{ Samoa } & Apia (user1) & $\begin{array}{l}\text { Medium-sized urban } \\
\text { centre }\end{array}$ & Digicel & Samsung J8 \\
\hline & Apia (user2) & $\begin{array}{l}\text { Medium-sized urban } \\
\text { centre }\end{array}$ & $\begin{array}{l}\text { Vodafone } \\
\text { Samoa (this } \\
\text { is Bluesky at } \\
\text { the start of the } \\
\text { time period) } \\
\end{array}$ & Samsung A30 \\
\hline \multirow{3}{*}{$\begin{array}{l}\text { Solomon } \\
\text { Islands }\end{array}$} & $\begin{array}{l}\text { Honiara } \\
\text { (user 1) }\end{array}$ & $\begin{array}{l}\text { Medium-sized urban } \\
\text { centre }\end{array}$ & bmobile & iPhone \\
\hline & $\begin{array}{l}\text { Honiara } \\
\text { (user 2) }\end{array}$ & $\begin{array}{l}\text { Medium-sized urban } \\
\text { centre }\end{array}$ & Our Telekom & Oppo 83 \\
\hline & East Kwaio & Rural area & Our Telekom & Oppo1701 \\
\hline
\end{tabular}


in various locations, as well as monitor for any changes over a period of six months. Time of day patterns, location type and impacts of weather were also taken into account.

To best understand internet speeds, quantitative data were collected. The focus was on the internet speeds experienced by end users rather than the internet speeds advertised by mobile network operators. This research was the first of its kind and encompassed several countries across the Pacific.

Smartphone users were approached and asked if they were willing to be research assistants. An information sheet outlining the research aims and processes was provided to potential research assistants. Table 2 contains details of the locations and telecommunication networks included in the study. Note that the network type accessed may have varied depending upon where the person was located when they undertook data collection. For instance, in Papua New Guinea, there are 2G, 3G and 4G networks available in different places (Highet et al., 2019, p. 19; Watson \& Park, 2019). Thus, it is possible that research assistants accessed different network generations as they moved about during the six-month-long period.

Research assistants used the Meteor application on their smartphones to determine and record internet speeds. Meteor is free-of-charge and easy-to-use. It is an 'internet speed test tool' (Google Play, 2020). It generates three figures in about 20 seconds: ping speed, download speed and upload speed. The Meteor application requires a small amount of data and therefore some research assistants were provided with regular, modest contributions towards their mobile telephone credit to enable their participation in the research.

An ordinary least squares (OLS) regression was used to test whether there was a ten per cent or higher increase or decrease in internet speeds for each research assistant over the six-month-long period of the study. It was necessary to include some confounding factors into the regression. This narrowed the inference of the regression results. For example, by including weather in the regression, we could be certain that any change in internet speeds found over time was a result of a change in the actual mobile internet speeds available to and experienced by the user, and not simply a result of heavy rainfall at the start of the study.

Data collection took place every Monday for six months, starting on Monday 6 January 2020. Research assistants took readings three times each Monday: morning (between 6am and midday), afternoon (between midday and $7 \mathrm{pm}$ ) and evening (between $7 \mathrm{pm}$ and midnight). Each set of readings was added to one row of a spreadsheet containing data entry columns for each of the following items:

- Date

- Exact time

- Network

- Location description (a free response column) 
- Built area description (a drop-down menu listed the following options: outdoors; indoors with bush material roof; indoors with tin roof; inside concrete/brick building; travelling in motor vehicle)

- $\quad$ Ping speed (measured in milliseconds [ms])

- Download speed

- Download speed units (a drop-down menu listed two options: megabytes per second $[\mathrm{MB} / \mathrm{s}]$ and kilobytes per second $[\mathrm{KB} / \mathrm{s}])$

- Upload speed

- Upload speed units (a drop-down menu listed two options: megabytes per second $[\mathrm{MB} / \mathrm{s}]$ and kilobytes per second $[\mathrm{KB} / \mathrm{s}]$ )

- Weather (a drop-down menu listed the following five options: clear sky; some clouds; mostly cloudy; rain; storm)

- Notes (a column where assistants could mention anything deemed relevant, or otherwise it could be left blank)

\section{Limitations}

Research assistants were recruited from amongst the existing professional and personal networks of the authors. Thus, some Pacific Island nations have not been included in the data collected. Overall, the research assistants tended to be based in urban centres and therefore rural areas are insufficiently represented in the data.

The data set is not representative of the overall population, so it cannot be used for wider population inferences. However, as data were collected over time, we can compare the change in speeds for the same users, with the same mobile handsets over the six-month period. Comparisons across locations are indicative only of the research assistants involved in the study. Importantly, this research does not draw conclusions about or attempt to compare the quality of mobile networks operated by different companies. A greater number of research assistants would be required in order to do that.

The weather categories stipulated as options in the spreadsheet provided to research assistants were somewhat amorphous and not discrete. Whether an assistant deemed the day to have 'some clouds' or to be 'mostly cloudy' was subjective. This may have made it difficult for assistants to complete this column of the spreadsheet.

The Meteor application is designed to detect a user's 'true connection speed, whether you're connecting through Wifi or your mobile network' (OpenSignal, 2020). Research assistants were asked to disable the Wifi option in their handset before taking readings from the mobile network. Although Wifi access is not common in the Pacific region, it is possible that on occasion research assistants may have in fact reported on Wifi speeds rather than mobile network speeds. While this is unlikely, it is a possible limitation of the data. 
Another possible limitation of the use of Meteor is that it was not designed for use with $2 \mathrm{G}$ networks. However, $2 \mathrm{G}$ networks are generally not considered suitable for internet use and thus this limitation is minimal, even though there are still 2G networks in existence in some parts of the Pacific Island region.

In the discussion section below, various factors that could influence internet speeds are outlined. This research was not able to adjust for all of these factors and thus regression results suffer from omitted variable bias. A future project may address this issue.

We could not include a variable for 'distance from tower' because we did not know the exact distance from the mobile device to the nearest mobile telephone tower. In future, the distance to the nearest telephone tower at each reading-point would be valuable to record. However, this was not considered feasible for this study. An alternative would be to ask participants to take readings at specific locations. These locations could then be introduced as categorical variables. Another option would be to use a smartphone application to collect exact location details through global positioning system (GPS) technology. However, the distance to the nearest telecommunication tower may be difficult to calculate, as it would require knowledge of the exact location of every tower within range of each research assistant's neighbourhood.

Though we collected consistent data across the Pacific, each location has just one to two mobile telephone users. We would need 30 users in each location to make statistically sound inferences about differences in location and other variables. Even so, we can make statistically sound inferences about changes over time.

\section{Data}

This section presents the internet speed data collected. Table 3 presents data collected from different locations in order from highest average download speed to the lowest. Note that in three locations (Madang, Apia and Honiara), data were collected for two networks. Data speeds across locations were generally as expected, with urban areas in Australia the best in terms of speed and consistency.

Figure 1 presents a box plot of download speeds. Port Moresby had considerably higher speeds than the other Pacific locations, with an average speed approximately 70 percent of that in Sydney, but with more variation than elsewhere. Outliers (greater than two standard deviations from the mean) are presented as dots.

The weekly routines and locations of the research assistants were generally consistent throughout the six-month-long period. The research assistants were reliable and dedicated. Many spreadsheets were completed in full. If a research assistant attempted to undertake a Meteor test but did not have any network signal at all, this was noted in the spreadsheet. For our purposes, such tests 


\section{Figure1: Distribution of Australia-Pacific download speeds, 2020}

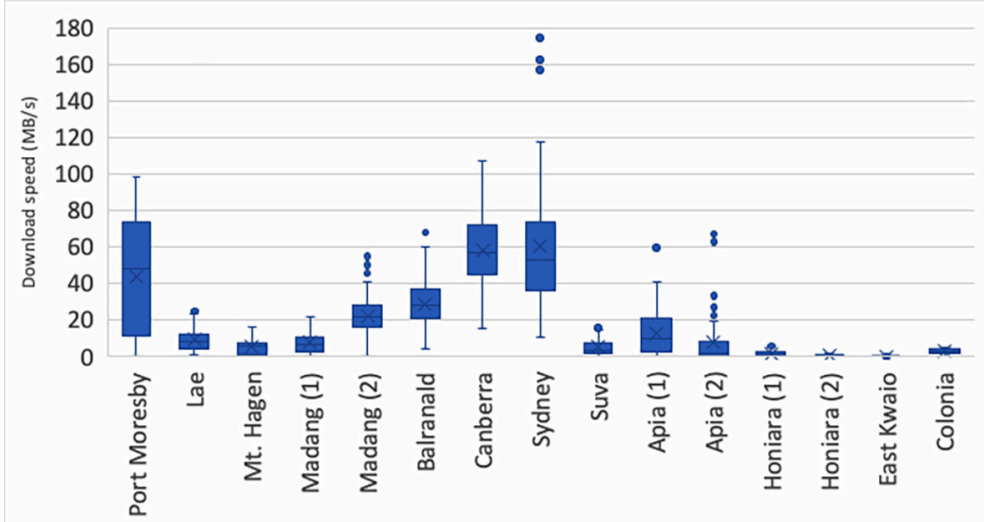

Note: Distribution of download speeds for 15 research assistants in Australia-Pacific locations, January 2020 - June 2020

were recorded as generating download speeds and upload speeds of zero, which reduced the average speed experienced by those users (see Table 3 ). When network connections were weak, high ping speeds with large numerical values were recorded but when there was no network signal, research assistants generally wrote zero in the ping speed column. This approach does not make sense for our purposes though, as lower ping speeds indicate better connections. Thus, in the case of ping speeds, zero values were replaced with high values (comparable to the highest ping speeds experienced in that location). Outlying values were also replaced with the otherwise highest values.

In rare instances, readings were missed because the research assistant was unwell or attending a funeral. There were some cases when the research assistant was unable to undertake readings because their handset battery was flat or they had no data. There was some limited travel within the person's immediate area or to another part of the same country and during most travel weekly readings continued uninterrupted.

In March to April 2020, the mobile network company Bluesky in Samoa was taken over by Amalgamated Telecom Holdings, branded as Vodafone (Amalgamated Telecom Holdings, 2020). During the transition period, the research assistant noticed unusually slow mobile internet speeds and subsequently saw official wording from the company explaining that the transition had caused disruptions to connectivity.

In April 2020, the Solomon Islands government instructed residents of the capital city Honiara to leave due to the threat of coronavirus (COVID-19) (Cain \& McGarry, 2020). One of the two research assistants based in Honiara left and returned to the natal village for eight weeks. At that location, there was no mobile internet access and therefore no readings were undertaken. The Fiji 


\begin{tabular}{|l|c|c|c|}
\hline Table 3: Average speeds accessed by user location, 2020 \\
\hline User location & $\begin{array}{c}\text { Average down- } \\
\text { load speed }\end{array}$ & $\begin{array}{c}\text { Average up- } \\
\text { doad speed }\end{array}$ & $\begin{array}{c}\text { Average ping } \\
\text { speed }\end{array}$ \\
\hline Sydney & 60.6 & 38.4 & 29.7 \\
\hline Canberra & 59.8 & 10.4 & 32.3 \\
\hline Port Moresby & 42.5 & 6.7 & 76.8 \\
\hline Balranald & 28.7 & 41.5 & 56.4 \\
\hline Madang (user 2) & 23.8 & 8.8 & 96.2 \\
\hline Apia (user 1) & 12.8 & 7.5 & 85.5 \\
\hline Apia (user 2) & 8.1 & 5.4 & 99.5 \\
\hline Madang (user 1) & 7.8 & 2.5 & 41.1 \\
\hline Lae & 9.9 & 2.6 & 21.8 \\
\hline Mount Hagen & 4.9 & 0.4 & 119.5 \\
\hline Suva & 4.8 & 1.1 & 238.7 \\
\hline Colonia & 2.7 & 0.5 & 163.3 \\
\hline Honiara (user 1) & 1.3 & 0.9 & 272.7 \\
\hline Honiara (user 2) & 0.3 & 0.1 & 340.6 \\
\hline East Kwaio & 0.03 & 0.01 & 5182.7 \\
\hline
\end{tabular}

Note: Average speeds accessed by 15 research assistants by user location, sorted from highest to lowest, January 2020 June 2020.

research assistant's smartphone was lost, which resulted in two weeks during which readings were not completed. The replacement handset was a similar model, using the same network.

The research assistant based in East Kwaio, which is a remote location in Solomon Islands, attempted to use a second mobile network on numerous occasions when the primary network had an outage. This practice was adopted to complete the scheduled Meteor tests for this research and it also reflects the strategy often employed by people in locations where networks are unreliable. On the whole, mobile internet speeds in that location were very poor, across both networks. The data from both networks were combined in the presentation of data from East Kwaio here. Cyclone Harold caused heavy rains in this area in early April 2020 but does not appear to have negatively impacted upon the already low and inconsistent internet speeds of the two networks nominally available in the area.

\section{Regression results}

Each user took three readings per week for six months, so changes in speeds over time for these users could be measured. Appendix 1 presents OLS regression 
results by location with download speed as the dependent variable. ${ }^{1}$ The data and graphs presented in this section of the article are referring to download speed, unless otherwise stated. This is because the data revealed similarities between ping speeds, download speeds and upload speeds in terms of trends. In other words, if there was a fast ping speed at a particular time and location, the download and upload speed were similarly high. As such, download speed is used here as an indicator of overall performance. All variables are dummy variables, except for 'time', which reflects the model's predicted change in speeds (in $\mathrm{MB} / \mathrm{s}$ ) over the course of the six-month research period in question.

Time of day variables were coded as morning (6am-8.59am), mid-morning (9am-11.59pm), lunch (12 noon-1.59pm), afternoon (2pm-5.59pm), evening (6pm-8.59pm) and night (9pm-12 midnight). This variable was coded to separate potential peaks and troughs in network usage during the day. These chunks can be affected by schedules that are common across large groups - that is, meal times, work hours and sleep.

The data indicated no statistically significant change in download speeds over six months for 11 of the 15 users, once variations in the time of day, weather and built area were taken into account. Taking these variables into account, two users (in Suva and Balranald) experienced increases in download speeds of $6 \mathrm{MB} / \mathrm{s}$ and $9 \mathrm{MB} / \mathrm{s}$ respectively over the six-month period. In Apia, user 1 experienced a drop in download speeds of $14 \mathrm{MB} / \mathrm{s}$ over the period, while the regression results showed that user 2 had an increase of around $14 \mathrm{MB} / \mathrm{s}$ overall (see Appendix 1). The latter reported lower speeds during the changeover from Bluesky to Vodafone after which a better service became available.

Cloudy and rainy days corresponded to lower speeds for 11 of the 15 users. The speeds for these users were approximately $10 \mathrm{MB} / \mathrm{s}$ lower than on clear days. Note that the regression results found little difference in the data speeds across the two cloudy categories: 'some clouds' and 'mostly cloudy'. For this reason, and for simplicity, the data from those two categories have been combined as 'clouds'. There is no 'storm' category appearing in Appendix 1 because the 'storm' option was only selected on three occasions by three different research assistants, so these three rare instances are shown as 'rain'.

There were no discernible patterns of variation in coefficients on the timeof-day across users. Ten of 14 users reported lower speeds while indoors under a tin roof compared to outdoors (the user in Canberra did not take any readings inside a building with a tin roof). Of the eight users who took readings inside a concrete or brick building, around half reported lower speeds once the other factors were taken into account.

\section{Summary of results}

This research generated a data set consisting of the mobile internet speeds 
experienced by 15 smartphone users in Australia and Pacific nations for a period of six months. The weekly routines and locations of the research assistants were generally consistent throughout the period. In cases of variation from an individual's standard routine, these have been outlined in the 'Data' section above.

Data speeds across locations were generally as expected, with urban areas in Australia the best in terms of speed and consistency. Port Moresby had considerably higher speeds than the other Pacific locations, but far greater variability in the quality of the service. The worst performer was the only rural, Pacific Island location included in the study.

The study set out to determine whether there were any differences over time. The data indicated no statistically significant change in download speeds over six months for 11 of the 15 users, once variations in the time of day, weather and built area were taken into account. The sale of a mobile telephone network may have affected the results in one of the other cases.

Although the coefficients on time-of-day variables were statistically significant in some cases, there were no clear patterns across locations. Cloudy and rainy days corresponded to lower speeds for 11 of the 15 users, compared to days with clear skies. Buildings appeared to interfere with signals, compared to readings taken outdoors.

\section{Discussion}

This article takes the digital divide concept as a key lens. The research has shown that in terms of the internet speeds experienced by internet users, a digital divide operates between locations. The research findings were largely as expected, in that urban areas in Australia provided access to the fastest speeds, while the one rural location in a Pacific Island nation included in the study had the slowest and weakest signal. This is the first study of its kind and thus it provides a useful comparison of the actual speeds available to end users in different localities (Table 3 and Figure 1 are particularly relevant in this regard).

It could be argued that inclusion of Australia in this study is unsuitable because it has much higher incomes per capita than the other nations included (UN ESCAP, 2018, pp. 12-13). Countries with high average incomes are likely to present attractive investment prospects for telecommunication companies eager to generate profits. By contrast, if there are typically low income levels in a nation, there may be less investment in telecommunication networks. Nonetheless, the authors feel that the inclusion of Australia provides a useful comparison for the purpose of understanding internet user experiences.

Differences over time were tested for the six-month-long period. It was anticipated that there could have been an improvement in speeds during the period due to the completion of the Coral Sea Cable System, the Kumul Submarine 
Cable and the Manatua One Polynesia Cable. However, there were no improvements in relevant places during the timeframe. Future research could provide a comparison to the data collected for this project during the first half of 2020 .

Time of day information was collected to ensure that differences in download speeds across peak and non-peak times were taken into account. Though there were some statistically significant differences across times of day in specific locations, these were not consistent across locations. The purpose of collecting this information was to adjust for differences across peak and non-peak times, to gain greater confidence in the coefficient on the 'time' variable, which estimates the movement in average speeds over the six-month period. For example, if an assistant took more early morning recordings (a non-peak time) at the start of the study, and more late morning recordings (a peak time) towards the end of the study this may skew the results.

Cloudy and rainy weather were found to be generally associated with slower internet speeds than were occasions with clear skies. The built area findings were somewhat inconclusive, perhaps due to variation between the routines of the research assistants. Further research would need to be undertaken to determine whether such factors correlate to the available internet speeds. Even so, there is some suggestion from this data set that lower speeds were experienced while indoors compared to outdoors.

In three towns (Madang, Honiara and Apia), data were collected for two different networks. While there were some differences in speeds for users in the same towns, the findings should not be interpreted as indicating that any one mobile network operator is providing faster speeds than another company is. The authors feel that further research with a larger number of smartphone users would be required before such comparisons could be made.

Various factors may affect the end speed experienced by a mobile telephone user. Data speeds could differ and either increase or decrease over time due to a wide range of factors such as technology upgrades, maintenance routines, or damage to infrastructure. Variability in congestion could be due to seasonal factors. Several key factors that may impact upon mobile internet speeds are discussed below.

\section{Network technology and infrastructure}

Telecommunication companies use different generations of network technology (see section two of this paper for a definition). The network generation and the quality of technology used for telecommunications infrastructure, including the type of cables and servers, influence data speeds.

\section{Regulatory settings}

Government regulatory settings can affect how the telecommunications ecosystem functions and potentially have an impact upon mobile data speeds. In the 
Pacific, improvements in terms of internet access have 'been attributed to regulatory policy reforms and other measures' (UN ESCAP, 2018, p. 7) but even so the region lags behind other parts of the world (GSMA, 2019) or continues to fall further behind (UN ESCAP, 2018, p. 13).

In many countries such as those included in this study, a key early move was to open up markets (Foster \& Horst, 2018, p. 9; Sagrista \& Matbob, 2016, p. 26). Governments and independent regulators often attempt to regulate the telecommunication sector, including individual uses (Foster \& Horst, 2018, p. 9; Kant, Titifanue, Tarai, \& Finau, 2018) and spectrum use by telecommunication companies (GSMA, 2019, p. 4). Businesses and civil society actors can also try to influence policy processes (for example in Fiji: Foster \& Horst, 2018, pp. 11-12).

The ability to enforce regulations can vary between countries. For example, in Papua New Guinea, the regulator's 'role is clear, but its enforcement capacity is weak' (World Bank, 2020, p. 47). Logan and Forsyth have argued that the dominance of the company Digicel in the country's mobile market has exacerbated this challenge (2018, p. 19; see also Suwamaru, 2015; Watson \& Fox, 2019).

\section{User device}

Finally, the quality of the parts and technology embedded in the user's mobile device may affect the download speeds experienced by the user. Handsets with newer technology and high-quality parts will tend to enable higher download speeds. There are also issues of compatibility, with some handsets only able to transfer data using $3 \mathrm{G}$ signals, even when $4 \mathrm{G}$ signals are available. In addition, age or damage to a device may reduce internet speeds.

\section{Conclusion}

The research has provided valuable insights into the mobile internet speeds available to consumers in the Pacific region for the first time. This multi-country research project has enabled comparisons of individual telephone users in various locations. Factors such as the time of day and weather were measured and taken into account when determining changes in speed over the six-month period.

The findings were largely as expected, with Australian readings demonstrating the availability of faster internet than those readings done in Pacific Island nations. Thus, the research has shown a real-life 'digital divide' between those with access to fast internet speeds and those with access to only slow speeds. Although fast speeds were available on occasion in Port Moresby, there were also cases of slow readings in the same city, suggesting inconsistency in terms of service provision. Despite the recent laying of undersea internet cables to Pacific Island nations included in this study, there was little evident improvement in internet speeds in these locations during the period January to June 2020. 
Quantitative data have been presented as the focus of this article. In cases in which research assistants varied their usual routine, their experiences were included in the paper to aid in the interpretation of the internet speeds collected. Research assistants were diligent but there were some gaps in the spreadsheets due to factors beyond their control. To further enrich understanding of everyday user experiences, future research could employ qualitative research methods such as individual interviews or group interviews.

The methodology could be employed again in the future, with possible modifications. A future project may adjust for handset type and other additional variables that could possibly interfere with network signals.

The method was effective in determining whether there was a change over time but it was not effective for testing factors such as being in a concrete building, for which more people would be required. Ideally, additional research would include data from a greater number of research assistants over a longer period.

It may be possible to use anonymised data from the Meteor application or a similar smartphone application but this data would only capture mobile internet speeds and would not include other contextual information such as the weather and location description. It may not be collected in a consistent manner at regular intervals.

Although this research was designed before the COVID-19 outbreak impacted upon international travel, it has been fortuitous that the method has enabled the continuation of a research program over a distance.

While this article focuses on quantitative data and uses technical terminology, it has clear relevance for media practitioners and scholars. Slow and unreliable internet speeds in some locations in the Pacific region could make media interviews through video calls unfeasible. Thus, slow mobile internet speeds could have a negative impact upon media operations and may limit the range of voices that can be heard.

\section{Note}

1. The Appendix 1 table can be accessed online at: https://ojs.aut.ac.nz/pacific-journalismreview/article/view/1168

\section{References}

ABC International Development. (2014). Governance and the role of media in Papua New Guinea. Retrieved from https://www.abc.net.au/cm/lb/9200956/data/governanceand-the-role-of-the-media-in-png---audience-research-data.pdf

Amalgamated Telecom Holdings. (2020). Financial statements for the year ended 31 March 2020. Retrieved from http://announcements.spx.com.fj/ftp/news/021727650.PDF AT Services. (2021, 19 January). Internet speed and bandwidth. Retrieved from https:// athelp.sfsu.edu/hc/en-us/articles/360050514614-Internet-speed-and-bandwidth

Ball, C., Francis, J., Huang, K.-T., Kadylak, T., Cotten, S. R., \& Rikard, R. V. (2019). The physical-digital divide: Exploring the social gap between digital natives and 
physical natives. Journal of Applied Gerontology, 38(8), 1167-1184.

Cain, T. N., \& McGarry, D. (2020, 8 April). Coronavirus in the Pacific: weekly briefing. Retrieved from https:/www.theguardian.com/world/2020/apr/08/coronavirus-in-thepacific-weekly-briefing

Curry, G. N., Dumu, E., \& Koczberski, G. (2016). Bridging the digital divide: Everyday use of mobile phones among market sellers in Papua New Guinea. In M. E. Robertson (Ed.), Communicating, networking: Interacting: The international year of global understanding (pp. 39-52). Cham, Switzerland: Springer International Publishing.

Donner, J. (2015). After access: Inclusion, development, and a more mobile internet. Cambridge, MS: MIT Press.

Foster, R. J., \& Horst, H. A. (2018). Introduction. In R. J. Foster \& H. A. Horst (Eds.), The moral economy of mobile phones: Pacific islands perspectives (pp. 1-17). Canberra, ACT: ANU Press.

Frontier. (2021). What is the best internet speed for streaming? Retrieved from https:// go.frontier.com/recommended-internet-speed-for-streaming

Google Play. (2020). Meteor. Retrieved from https://play.google.com/store/apps/ details? $\mathrm{id}=$ meteor.test.and.grade.internet.connection.speed \&hl=en\&gl=US

GSMA. (2019). The mobile economy: Pacific islands. Retrieved from http://www.gsma. com/mobileeconomy/pacific-islands/

Harris, M. (2019, 16 June). Is your broadband fast enough to stream audio? Retrieved from https://www.lifewire.com/is-my-broadband-fast-enough-to-stream-audio-2438444

Highet, C., Nique, M., Watson, A. H. A., \& Wilson, A. (2019). Digital transformation: The role of mobile technology in Papua New Guinea. Retrieved from London, UK: https:/www.gsma.com/mobilefordevelopment/resources/digital-transformation-therole-of-mobile-technology-in-papua-new-guinea/

Kant, R., Titifanue, J., Tarai, J., \& Finau, G. (2018). Internet under threat?: The politics of online censorship in the Pacific Islands. Pacific Journalism Review : Te Koakoa, 24(2), 64-83. https://doi.org/10.24135/pjr.v24i2.444

Logan, S., \& Forsyth, M. (2018). Access all areas? Telecommunications and human rights in Papua New Guinea. Human Rights Defender, 27(3), 18-20.

nbn co ltd. (2020). What exactly is ping, and what affects it? Retrieved from https://www. nbnco.com.au/blog/entertainment/what-is-ping-and-what-affects-it

OpenSignal. (2020). OpenSignal apps. Retrieved from https://www.opensignal.com/apps Ragnedda, M. (2018). Tackling digital exclusion: Counter social inequalities through digital inclusion. In G. W. Muschert, K. M. Budd, M. Christian, B. V. Klocke, J. Shefner, \& R. Perrucci (Eds.), Global agenda for social justice: Volume one (pp. 151-158). Bristol, UK: Bristol University Press.

Robinson, L., Schulz, J., Blank, G., Ragnedda, M., Ono, H., Hogan, B., . . . Khilnani, A. (2020). Digital inequalities 2.0: Legacy inequalities in the information age. First Monday, 25(7). http://dx.doi.org/10.5210/fm.v25i7.10842

Rogerson, S. (2020). The digital divide is a multi-dimensional complex. Journal of Information, Communication and Ethics in Society, $18(3), 321$.

Sagrista, M., \& Matbob, P. (2016). The digital divide in Papua New Guinea: Implications for journalism education. Pacific Journalism Review : Te Koakoa, 22(2), 20-34. https://doi.org/10.24135/pjr.v22i2.44

Singh, S. (2020). The media and journalism challenges in Melanesia: Addressing the impacts of external and internal threats in Fiji, Papua New Guinea, Solomon Islands and Vanuatu . Pacific Journalism Review : Te Koakoa, 26(1), 48-62. https://doi. org/10.24135/pjr.v26i1.1095 
Suwamaru, J. K. (2015). Status quo and emerging challenges in information and communication technology for Papua New Guinea. In SSGM In Brief 2015/7. Canberra, ACT: Australian National University.

Telstra. (n.d.). What does 'download' and 'upload' mean? Retrieved from https://www. telstra.com.au/support/category/broadband/nbn/speeds-and-usage/what-do-the-termsdownload-and-upload-mean

UN ESCAP. (2018). Broadband connectivity in Pacific Island countries. Retrieved from https://www.unescap.org/sites/default/files/Broadband\%20Connectivity\%20in\%20 Pacific\%20Island\%20Countries.pdf

van Dijk, J. A. G. M. (2005). The deepening divide: Inequality in the information society. Thousand Oaks, CA: Sage Publications.

Watson, A. H. A., \& Fox, R. (2019, 16 May). A tax on mobile phones in PNG? Retrieved from https://devpolicy.org/a-tax-on-mobile-phones-in-png-20190516/

Watson, A. H. A., \& Park, K. R. (2019, 13 August). The digital divide between and within countries. Retrieved from https://devpolicy.org/the-digital-divide-betweenand-within-countries-20190813/

Williams, P. (2019). Connecting Papua New Guinea: The dawn of the digital era. Retrieved from https://www2.deloitte.com/au/en/pages/technology/articles/connectingpapua-new-guinea.html

World Bank. (2020). In the time of COVID-19: From relief to recovery. Retrieved from http://png/publication/papua-new-guinea-in-the-time-of-covid-19---from-relief-torecovery

\section{Acknowledgements}

The authors wish to extend their sincere appreciation to the research assistants who voluntarily collected data using their smartphones. With their permission, we list their names here in alphabetical order by first name: Elizabeth Pundu, Emil Yambel, Fiafaitupe TLafaele, Jennifer Appo, Joseph Pundu, Madeleine Manning, Paul Hadlow, Rosie Wisbey, Solomon Islands Chamber of Commerce and Industry, Tara Patu, Tommy Esau, Wendell Setham, William Waqavakatoga, and Yaling Tapo. The Department of Pacific Affairs at Australian National University provided funding for mobile data for those research assistants who needed it through the Australian Government-funded Pacific Research Program grant.

Dr Amanda H. A. Watson is a research fellow with the Department of Pacific Affairs at Australian National University. Her research focuses on mobile telephone uptake and use in the Pacific region. Research interests include telecommunication regulation, communicative practices, communication-for-development, and media strategies.

amanda.watson@anu.edu.au

Rohan Fox is a research officer with the Development Policy Centre at the Australian National University. His research focuses on the Papua New Guinean economy. 